UDC 130.2

LBC 87.6

\title{
PLATO'S "REPUBLIC": SAMPLE OF PROTO-PROJECT MENTAL ACTIVITY AND PRIMARY EXPERIENCE IN THE DESIGN OF NEW SOCIAL FORMS
}

\author{
Polina V. Rybalkina \\ V.Ya. Gorin Belgorod State Agricultural University, hous. est. Maysky, Belgorod Region, \\ Russian Federation
}

\begin{abstract}
The author devotes the article to the analysis of Plato's "Republic" in the context of the Genesis of project thinking and project activity as an anthropological result going back to the early stages of culture and primary personality-oriented ancient practices. The research attempts to trace the scheme of the movement of "project ideas" proposed by Plato "designer". Later these ideas would be widely known as "an ideal state" and for many centuries would become a model of government. Plato's "project ideas" considered by the author still remain in demand and are actively used in contemporary project cultural practices.

For this purpose, the author makes the transition to the plane of historical and cultural retrospective of the origin of project thinking phenomenon with the objective twists and turns of its genesis. The author also attempts to reflect on this process, to study and clarify a number of points related to the prelude and dynamics of the development of the project approach to the organization of modern reality. At the same time, the text substantiates the author's position on the interpretation of Plato's "Republic" as an early typical example of Proto-project thinking formed in the depths of ancient cultural practices. Project thinking is a promising project of the existence of culture, a kind of matrix of self-realization of a significant part of our contemporaries.

The main conclusion of the study is the ability to recognize the work of Plato "State" as one of the first samples of proto-design on the basis of the presence of a large number of typological features of design and the absence of a smaller number of such. We believe that Plato's work "Republic" on most parameters falls under the concept of "project activity", because in it we were able to identify most of the components of socio-cultural design.

Key words: project development, project, project thinking, man, subject, object, genesis.
\end{abstract}

УДК 130.2

ББК 87.6

\section{«ГОСУДАРСТВО» ПЛАТОНА: ОБРАЗЕЦ ПРОТОПРОЕКТНОЙ МЫСЛЕДЕЯТЕЛЬНОСТИ И ПЕРВИЧНЫЙ ОПЫТ ПРОЕКТИРОВАНИЯ НОВЫХ СОЦИАЛЬНЫХ ФОРМ}

\author{
Полина Валерьевна Рыбалкина \\ Белгородский государственный аграрный университет им. В.Я. Горина, п. Майский, Белгородская область, \\ Российская Федерация
}

\footnotetext{
Аннотация. Статье проводится аналитика работы Платона «Государство» в контексте генезиса проектного мышления и проектной деятельности как антропологического результата, восходящего к ранним стадико известны под названием «идеальное государство» и на многие века станут образцом государственного устройства, активно использующимся в современных культурных проектных практиках. С этой целью осуществляется переход в плоскость историко-культурной ретроспективы зарождения феномена проектного мышления с объективными перипетиями его генезиса; предпринимается попытка отрефлектировать данный процесс, изучить и прояснить ряд моментов, связанных с прелюдией и динамикой развития проектного

(?) подхода к организации современной действительности. Одновременно по тексту обосновывается авторская
} 
позиция относительно трактовки «Государства» Платона как раннего типического образца протопроектного мышления, формирующегося в недрах античных культурных практик. Проектное мышление является перспективным проектом бытия культуры, своего рода матрицей самореализации значительной части наших современников.

Итогом проведенного исследования становится признание труда Платона «Государство» одним из первейших образцов протопроектирования на основании наличия большего и отсутствия меньшего количества типологических признаков проектирования. Утверждается, что данная работа по большинству параметров подпадает под понятие «проектная деятельность», поскольку в ней удалось выявить большинство составляющих социокультурного проектирования.

Ключевые слова: проектирование, проект, проектное мышление, человек, субъект, объект, генезис.

В рамках заявленной темы, прежде всего, отметим следующее. На данный момент становится очевидной неоспоримая роль проектной мыследеятельности в современном обществе и его культуре, а также миссия непосредственного «агента» проектирования носителя и генератора проектного мышления, обладающего знаниевым, в том числе интеллектуальным, капиталом. Последнего мы рассматриваем как «человека проектирующего и проектируемого» - «homo projectus» [7, с. 17].

Следует отметить, что данный концепт достаточно активно используется исследователями в современных науках гуманитарного направления. В частности, в трудах К.В. Сосновской [7] культурно-исторический феномен проектного мышления обосновывается в качестве универсального инструмента социокультурного проектирования настоящего и будущего. Работы В.Н. Глазунова [1], И.В. Никулина [2], М.К. Петрова [3] наглядно отражают то, как проектирование, проектное мышление и проектная деятельность вошли в нашу жизнь. На самом деле, внимательно изучив сегодняшний мир и «модульного человека», который, по выражению французского философа Ж.-П. Сартра [6, c. 200], во многом неустанно творит себя, одновременно существуя в некоем мираже, когда будущее реальнее настоящего, мы увидим, что в проектной культуре третьего тысячелетия роль проектно-мыслительной деятельности в целевом преобразовании культурных практик будущего не подлежит сомнению.

Хотя говорить об экспансии и тотальности проектирования нашей жизни и самого человека было бы преждевременно, тем не менее такие концепты, как «проект», «проектная мыследеятельность», «проектное мыш- ление», «проектный подход» и ряд синонимичных понятий не просто на слуху сегодня - они прочно и практически повсеместно вошли в нашу культуру.

Bce это лишь подтверждает развиваемую нами в цикле более ранних публикаций мысль о том, что проектное мышление является перспективным проектом бытия культуры, своего рода матрицей самореализации значительной части наших современников. Мы, безусловно, признаем, что данный феномен проник во все сферы современной жизни, усиливаясь через интеграционные процессы, происходящие в мировой культуре и сфере общечеловеческого созидания новейшего миропорядка. Под давлением инновационных практик проектного мышления современный человек, с одной стороны, организует свои жизненные реалии, практикуя новые проектные формы социального и культурного действия и взаимодействия, однако с другой существо данного феномена культуры в его целостной концептуализации не представляется возможным без обращения к истокам, к началу, к некоторой «точке отсчета» (если таковую вообще возможно строго зафиксировать в эволюции проектной/протопроектной культуры).

Полагаем, что для этого необходимо предпринять попытку перехода в плоскость историко-культурной ретроспективы зарождения феномена проектного мышления с объективными перипетиями его генезиса. Попытаемся отрефлектировать данный процесс и прояснить ряд моментов, связанных с возникновением и дальнейшей динамикой развития проектного подхода к организации действительности. Вначале отметим следующее: изучая панораму исторического становления проектного мышления как метода и способа прак- 
тической деятельности человека по организации социальной, культурной и мыслительной деятельности и жизненных процессов, мы соглашаемся с исследователями, утверждающими, что «...в рамках субъект-объектной и субъект-субъектной парадигмы зачатки проектного мышления обнаруживаются уже в античной культуре» [5, с. 25]. В частности, там, где философы проблематизировали состояние настоящего и прорисовывали образы желаемого будущего, мысленно выстраивали логику и структуру идеального общества и считали, что построение его модели в реальном мире возможно за счет тщательного копирования в действительности элементов идеальной модели общества, разработанной мудрецами. Попытки осмыслить первичный опыт по проектированию новых социальных форм, организовывать и направлять культурные и социальные процессы и практики конструирования новой модели общества и человека уже присутствуют в классических античных сочинениях Платона, Аристотеля, Демокрита, Гераклита, Сенеки, Цицерона и др. В этой связи мы сочли целесообразным обратиться к труду Платона «Государство», на примере которого попытаемся доказать факт зарождения феномена проектного мышления и возникновения первых опытных социокультурных проектов и практик, направленных на изменение как самого человека, так и его жизненных реалий.

Внимательное знакомство с работой Платона «Государство» в первую очередь показывает, что философ поднимает крайне важный социальный вопрос о возможности реализации попытки создать идеальное государство, в котором все полно смысла и порядка, а также создается в соответствии с требованиями людей. В этом мы усматриваем первую необходимую составляющую понятия «социокультурное проектирование»: очевидный запрос общества, вызванный социальными и/или культурными нуждами и проектировщик, предлагающий возможные варианты решения назревших проблем. Здесь, на наш взгляд, Платон вступает в первую фазу проектной деятельности: замысла или целеполагания, на которой проектировщик (в данном случае - сам мыслитель) ставит цель. Он пишет: «Осуществление такого строя вполне возможно, о невозможном мы не говорим, а что это трудно, признаем и мы» [4, с. 17]. Философ поднимает вопрос о понятии мысленного, построенного с начала государства, а далее говорит о том, что мысленное построение еще нужно реализовать в жизни. Мы считаем, что это признак второй фазы проектного мышления и проектной деятельности: анализа реалистичности проекта, другими словами - фаза инвентаризации. На данном этапе, по нашему мнению, проходили активные общественные дискуссии и обсуждения, в которых оппоненты возражали философу, утверждая, что его идеи лишь чистое воображение и фантазия, и вряд ли его проект когда-либо может быть осуществлен. Предполагаем, что это признак фазы субъект-субъектных отношений, в которой проектировщику приходится вступать во взаимодействие с другими индивидуумами, не разделяющими его взглядов и имеющими свои собственные, кардинально отличающиеся проекты с совершенно иными целями, заложенными на фазе целеполагания.

Выступая в роли проектировщика в рамках труда «Государство», Платон действовал по схеме, подпадающей под определение «проектное мышление» и «проектная деятельность». В самом общем виде она может быть представлена таким образом:

- во-первых, дается критическая оценка существовавших на тот момент форм государственной жизни, что является необходимым компонентом проектной деятельности, направленной на изменение системы;

- во-вторых, предложены собственноплатоновские варианты видения «правильного» государственного устройства (модель «идеального государства»), то есть мысленно создается и предлагается античному обществу проект перестройки как общественной системы, так и людей, вовлеченных в нее.

- в-третьих, проектировщиком формулируется целый комплекс идей, которые в последующем в значительной мере предопределили тематику государственного устройства, то есть разработан план реализации проекта. Здесь необходимо уточнить, что Платон выступал лишь в качестве теоретизирующего проектировщика, постольку дальнейшего развития его проектная деятельность не получила. То есть, пройдя фазы целеполагания, ин- 
вентаризации и перейдя к стадии субъектсубъектных отношений, философ так и не приступил к осуществлению проекта. Таким образом, он не стал практиком государственного строительства и не предпринял никаких реальных попыток его переустройства, в конечном итоге переведя практическую проектную деятельность в плоскость мысленную. Платон говорил: «Проектирование - это прежде всего то, что создается как объект, но создается в мысли» [4, с. 17].

Обобщая сказанное, выразим свою позицию: мы понимаем и принимаем логику философа, так как она полностью согласовывалась с понятиями идеалистической философии, согласно которой первичному миру идей соответствовал вторичный мир вещей. Соответственно, государство уже было создано демиургом, и душе человека оставалось лишь правильно припомнить эту идею. Поэтому Платон и не пытался перейти к практическим действиям, направленным на реализацию предложенного им же проекта, а постоянно призывал социум к напряженной мысленной работе, то есть к теоретическому проектированию: «...тому, кто действительно направил свою мысль на бытие, уже недосуг смотреть вниз, на человеческую суету и, борясь с людьми, преисполняться недоброжелательства и зависти (здесь представлена сначала оппозиция реальной жизни. - П. В.). Видя и созерцая нечто стройное и вечно тождественное, не творящее несправедливости, от нее не страдающее, полное порядка и смысла, он этому подражает и как можно более ему уподобляется» [4, с. 32].

Примечательно, что известный российский философ и культуролог, работы которого посвящены проблематике проектного мышления и проектной мыследеятельности, В.М. Розин указывает на важный нюанс: «Обратите внимание, - пишет он, - это не только строительство государства сначала как бы в мысли, в мышлении, но, оказывается, уже есть как бы своеобразный образ государства как нечто стройное, вечно тождественное, где нет несправедливости, полное порядка и смысла, говоря: вот этому надо подражать, но подражать, естественно, выстраивая это в мысли» [5, с. 9]. Платон теоретизирует и предлагает разные стратегии мысленного, а не прак- тического создания «идеального государства». Одна из предложенных им стратегий - найти правителя, который бы взял на себя эту заботу: «...почему бы нет, ...если найдется правитель, который заинтересуется этим мероприятием...» [4, с. 30$]$.

Иными словами, Платон либо совсем не претендует на роль реализатора проекта, желая остаться лишь теоретиком, либо пытается переложить ответственность за практическое осуществление предложенной им идеи на кого-то другого. По нашему мнению, такая пассивная теоретическая позиция тоже подпадает под понятие проектной деятельности, когда проект замышляется одним индивидуумом, а реализуется другим (другими) в рамках субъект-субъектной парадигмы. Здесь мы бы предложили определить позицию Платона - проектировщика как нереализованную реализацию. Данный термин, в нашем понимании, представляет собой мыслительный процесс, замещающий реальное воплощение проекта, мысленный эквивалент деятельности, симулякр. «Нереализованная реализация», не будучи воплощенной в действительности, не вносит субъективных или объективных изменений в окружающий мир, поскольку не взаимодействует с жизненными реалиями напрямую. Она лишь предполагает, мысленно «примеряет» к ситуации возможные потенциальные изменения, «перебирает» виртуальные варианты будущего, в которых проектировщик видит себя (субъект проектирования) и других (объекты проектирования) в желаемых состояниях, созданных его воображением. Феномен «нереализованной реализации» также предполагает последующее оценивание миновавших событий и состояний с позиции «как бы из будущего», с той точки, где проектировщик хотел бы оказаться. Платон продолжает активно выдвигать проектные идеи по реорганизации существовавшей действительности, не переходя однако к конкретным практическим действиям. Филососф предлагает достаточно детальный план изменения жизни людей, сравнив их с узниками пещеры. Узники не живут реальной жизнью, все, что они видят - лишь тени реальности. Единственный способ начать жить по-настоящему заключается в выводе человека из пещеры. Здесь Платон рассуждает, при каких условиях это 
возможно: «Если же кто станет насильно тащить его по крутизне вверх из пещеры в гору и не отпустит, пока не извлечет его на солнечный свет, разве он не будет страдать и не возмутиться таким насилием? Тут нужна привычка, раз ему предстоит увидеть все, что там, наверху. Начинать надо с самого легкого. Сперва смотреть на тени, затем на отражение в воде людей и различных предметов, а уж потом на самые вещи. И, наконец, я думаю, что этот человек был бы в состоянии смотреть уже на самое Солнце, находящееся в его собственной области, и усматривать его свойства, не ограничиваясь наблюдением его обманчивого отражения в воде или чуждых ему предметов» [4, с. 17].

Комментируя данный фрагмент, заметим, что философ-проектировщик прекрасно понимал, как трудно насильно «вывести человека из пещеры на свет». Людям «проектируемым», вовлеченным в проект, придется проходить через длительную процедуру с этапами обучения новому образу восприятия новых жизненных реалий, норм поведения и мышления. Для достижения намеченной цели проекта придется предпринять не только физические, но и интеллектуальные усилия. Но насколько готовы прилагать усилия те, ради кого Платон замышляет данный проект? Философ рефлектирует по поводу практической несостоятельности предложенных идей, ведь их так и не удалось реализовать в греческом обществе. «Нарисованный» Платоном проект «идеального государства» оказался утопической фикцией. Он пишет: «Всему указанному сейчас вряд ли когда-нибудь выпадет удобный случай для осуществления, так, чтобы все случилось согласно нашему слову. Вряд ли найдутся люди, которые будут довольны подобным устройством общества, и которые не обладали бы золотом и всем тем, что будет запрещено законодателем. А что такие запрещения будут - это ясно из всего сказанного выше» [4, с. 19]. Мы считаем, что на этом этапе рассуждений Платон вступает в фазу анализа результатов своей так и нереализованной проектной деятельности. В данном случае это провал, неудача. Философ и сам понимал обреченность предложенного им проекта реорганизации государственного устройства: «...вряд ли найдутся люди, которые вый- дут из пещеры. Все это точно рассказ о сновидении, точно искусная лепка государства и граждан из воска» $[4$, с. 19]. Не имея возможности перейти к стадии наслаждения полученным от реализации проекта результатом, Платон пессимистично формулирует вывод: «Я также отрицаю возможность для людей, за исключением немногих, стать счастливыми и блаженными» [4, с. 19].

Резюмируя изложенное выше, обощим некоторые наблюдения. Во-первых, работа Платона «Государство» по большинству параметров подпадает под понятие «проектная деятельность», поскольку в ходе анализа было выявлено наличие достаточного количества элементов, являющихся составляющими понятия «социокультурное проектирование», а именно:

- социального заказа, сформированного требованиями времени и социокультурной ситуацией;

- фазы целеполагания;

- фазы инвентаризации;

- фазы вступления в субъект-субъектные отношения;

- фазы анализа.

Однако считаем необходимым отметить, что нами выявляются не только характеристики собственно проектной деятельности, но и ее некоторые так называемые антиподы, не позволяющие идентифицировать платоновский протопроект с «чистым проектом» в современном его смысловом сущностном значении и трактовке.

Во-вторых, у Платона отсутствует фаза реализации проекта: философ не пошел дальше теоретизирования, ограничившись сферой «мысленного строительства». Соответственно, отсутствует и фаза наслаждения полученным результатом, поскольку проект не был осуществлен.

В-третьих, с учетом некоторых изложенных выше нюансов, мы полагаем возможным считать работу Платона «Государство» одним из первейших образцов протопроектирования (прежде всего, на основании наличия в ней большего и отсутствия меньшего количества типологических признаков проектирования).

С нашей точки зрения на общем фоне проектной культуры XXI в. роль проектно- 
мыслительной деятельности в целевом преобразовании культурных практик будущего неоспорима. Мы полагаем, что протопроект Платона «Государство» - типический образец, прелюдия проектирования в современном значении данного феномена. Без такого раннего и несомненно позитивного проектного опыта вряд ли стало возможным бурное развитие сегодняшних культурных практик, восходящих своими истоками к первичным формам человеческой мыследеятельности.

\section{СПИСОК ЛИТЕРАТУРЫ}

1. Глазунов, В. Н. Концептуальное проектирование: теория изобретательства / В. Н. Глазунов. M. : URSS, 2018. -512 c.

2. Никулин, И. В. Оценка проектных рисков в системах взаимного рефлексивного управления / И. В. Никулин. - Воронеж : Научная книга, 2009. $-126 \mathrm{c}$.

3. Петров, М. К. Самосознание и научное творчество / М. К. Петров. - Ростов н/Д : Ростов, 1992. $-272 \mathrm{c}$. $448 \mathrm{c}$

4. Платон. Государство. - М. : Логос, 1971.-

5. Розин, В. М. Социокультурное проектирование и программирование: методологическое исследование / В. М. Розин. - M. : URSS, 2018. - 160 с.
6. Сартр, Ж.-П. Последний шанс / Ж.-П. Сартр ; пер. с. фр. А. Колотова, Ю. Яхминой, Л. Зониной. СПб : Азбука, 2000. -464 с.

7. Сосновская, К. В. Проектное мышление в бытии человека : дис. ... канд. филос. наук / Сосновская Ксения Владимировна. - Омск, 2013. - 132 с.

\section{REFERENCES}

1. Glazunov V.N. Kontseptualnoe proektirovanie: teoriya izobretatelstva [Conceptual Design: Theory of Invention]. Moscow, USSR Publ., 2018. 512 p.

2. Nikulin I.V. Otsenka proektnykh riskov v sistemakh vzaimnogo refleksivnogo upravleniya [Evaluation of Project Risks in the Systems of Mutual Reflexive Management]. Voronezh, Nauchnaya kniga Publ., 2009. 126 p.

3. Petrov M.K. Samosoznanie i nauchnoe tvorchestvo [Self-Consciousness and Scientific Creativity]. Rostov-on-Don, Postov Publ., 1992. 272 p.

4. Plato. Gosudarstvo [State]. Moscow, Logos Publ., 1971. 448 p.

5. Rozin V.M. Sotsiokulturnoe proektirovanie $i$ programmirovanie: metodologicheskoe issledovanie [Socio-Cultural Design and Programming: Methodological Research]. Moscow, URSS Publ., 2018. $160 \mathrm{p}$.

6. Sartre J.-P. Posledniy shans [The Last Chance]. Sain Petersburg, Azbuka Publ., 2000. 464 p.

7. Sosnovskaya K.V. Proektnoe myshlenie v bytii cheloveka: dis. ... kand. filos. nauk [Projective Thinking in Human Being. Dr. philos. sci. diss.]. Omsk, 2013. 132 p.

\section{Information about the Author}

Polina V. Rybalkina, Specialist in Educational and Methodical Work of the International Relations Department, V.Ya. Gorin Belgorod State Agricultural University, Vavilova St., 1, 308503 hous. est. Maysky, Belgorod Region, Russian Federation, tulinowa.polina@yandex.ru.

\section{Информация об авторе}

Полина Валерьевна Рыбалкина, специалист по учебно-методической работе отдела по международным связям, Белгородский государственный аграрный университет им. В.Я. Горина, ул. Вавилова, 1, 308503 п. Майский, Белгородская область, Российская Федерация, tulinowa.polina@yandex.ru. 